\title{
ALOCAÇÃO DE LINHAGENS DE MILHO DERIVADAS DAS POPULAÇÕES BR-105 E BR-106 EM GRUPOS HETERÓTICOS
}

\author{
Rogério de Melo Costa Pinto; Antonio Augusto Franco Garcia²; Cláudio Lopes de Souza Jr.3* \\ ${ }^{1}$ Depto. de Ciências Agrárias e Ambientais - UESC, Rod. Ilhéus-Itabuna, km.16 - CEP: 45650-000 - Ilhéus, BA. \\ 2 Depto. de Ciências Exatas, USP/ESALQ, C.P. 9 - CEP: 13418-900 - Piracicaba, SP. \\ ${ }^{3}$ Depto de Genética, USP/ESALQ, C.P. 83 - CEP: 13418-900 - Piracicaba, SP. \\ *Autor correspondente <clsouza@carpa.ciagri.usp.br>
}

RESUMO: Os grupos heteróticos são importantes no melhoramento de milho, pois permitem o uso mais eficiente do germoplasma. Assim, o objetivo deste trabalho foi alocar linhagens de milho em grupos heteróticos a partir de estimativas da capacidade específica de combinação. Oito linhagens $S_{3}$ da população BR-105 e dez da BR-106, foram cruzadas ao nível interpopulacional seguindo um sistema dialélico. Oitenta híbridos simples foram obtidos e avaliados em látices em três ambientes. Foram avaliados os caracteres produção de grãos (PG), altura da planta (AP) e altura da espiga (AE). As estimativas das capacidades geral (CGC) e específica (CEC) de combinação foram obtidas segundo o método 4, modelo I de Griffing. A partir das estimativas de CEC, as linhagens foram alocadas aos respectivos grupos heteróticos utilizando-se o método UPGMA (média aritmética não ponderada) para a construção do dendrograma e a dispersão gráfica pelo método das coordenadas principais. Para PG, as linhagens foram alocadas em quatro grupos heteróticos, sendo dois grupos em cada população. Para AP e AE, o uso das estimativas de CEC não foi eficiente para alocar as linhagens em grupos heteróticos. As análises de agrupamento e de coordenadas principais foram eficientes na alocação das linhagens em grupos heteróticos para PG. Então, como a produção de grãos é a principal característica para o melhoramento de milho, com a alocação das linhagens em quatro grupos heteróticos, os cruzamentos serão direcionados e o processo de melhoramento se tornará mais eficiente, evitando a obtenção e a avaliação de cruzamentos (híbridos) desnecessários.

Palavras-chave: Zea mays, cruzamento dialélico, capacidade de combinação

\section{ALLOCATION OF MAIZE LINES FROM BR-105 AND BR-106 POPULATIONS TO HETEROTIC GROUPS}

\begin{abstract}
The heterotic groups are important in maize breeding programs because they allow the most efficient use of the germoplasm. The objective of this research was to allocate maize lines to heterotic groups from estimates of specific combining ability (SCA). Eight and ten $\mathrm{S}_{3}$ lines derived from populations BR-105 and BR-106, respectively, were crossed at interpopulation levels following a diallel system. Eighty singlecrosses were obtained and evaluated in lattice designs across three environments. Recorded data consisted of grain yield (GY), plant height $(\mathrm{PH})$ and ear height $(\mathrm{EH})$. Estimates of general and specific combining ability (GCA) and (SGA) were computed according to Griffing's method 4, model I, for all traits. Estimates of SCA were used for principal coordinate analysis (PCO) and for cluster analysis, by using UPGMA (unweighted pair-group method with arithmetical averages) clustering algorithm, to assign the lines to heterotic groups. For the trait GY the lines were allocated to 4 heterotic groups, in which the lines from each population were subdivided in 2 heterotic groups. For the traits $\mathrm{PH}$ and $\mathrm{EH}$, the use of the estimates of SCA to assign lines to heterotic groups were not efficient. Cluster analysis and principal coordinate analysis were efficient for the trait GY in allocating maize lines to heterotic groups. Thus, since grain yield is the main trait for the breeding purposes, with the allocation of the lines in 4 heterotic groups, the crosses will be more efficient, avoiding to obtain and evaluate unnecessary (hybrid) crosses.
\end{abstract}

Key words: Zea mays, diallel analysis, combining ability

\section{INTRODUÇÃO}

A utilização de padrões heteróticos em programas de melhoramento, visando a obtenção de híbridos de milho, constitui uma estratégia que permite explorar e capitalizar a heterose. O desenvolvimento de híbridos superiores depende da capacidade de combinação das linhagens envolvidas na produção desses, sendo que a obtenção de híbridos que expressam alta magnitude da heterose é maior nos cruzamentos entre linhagens não aparentadas do que entre as aparentadas (Hallauer, 1990). Nos programas de melhoramento de milho, usualmente as linhagens de um grupo heterótico são avaliadas em cruzamentos com algumas linhagens elites derivadas de outro grupo heterótico (teste crosses). Por causa do número elevado de linhagens a serem avaliadas, torna-se impossível a realização de todos os cruzamentos. Com isso, perde-se a oportunidade de se avaliarem todos os híbridos possíveis (Smith, 1986). Com a separação das 
linhagens em grupos heteróticos pode-se diminuir os cruzamentos e as avaliações dos híbridos em experimentos com repetições e aumentar a eficiência do programa.

Dentre os métodos destinados a avaliar a divergência genética das linhagens, citam-se as análises de cruzamentos dialélicos, que avaliam as capacidades geral (CGC) e específica (CEC) de combinação, estabelecidas por Sprague \& Tatum (1942). Os conceitos da CGC e CEC são úteis na caracterização das linhagens em cruzamentos, sendo que a CGC está associada principalmente a genes de efeito aditivo e a CEC depende basicamente de genes de efeito não aditivo (dominância e epistasia). Os cruzamentos dialélicos têm sido muito usados no melhoramento de milho e se mostrado eficientes para detectar divergências genéticas entre as linhagens e a alocação destas em grupos heteróticos distintos (Han et al., 1991; Gonzalez et al.,1997; Terron et al., 1997). A nova população formada a partir de linhagens, em geral, apresenta menor depressão por endogamia e tende a ser uma fonte de novas linhagens superiores (Vasal et al., 1992c).

No presente trabalho foram utilizadas linhagens das populações de milho tropical BR-105 e BR-106, as quais apresentam heterose de magnitude elevada em cruzamentos (Naspolini Filho et al., 1981; Souza Jr. et al., 1993), o que significa que pertencem a grupos hetróticos distintos. As populações de milho tropical geralmente são compostos com grande variabilidade genética, o que gera dificuldades na alocação de suas linhagens em grupos heteróticos distintos. Então, além da separação das populações em grupos heteróticos, dentro das populações existe variabilidade suficiente para a formação de novos grupos heteróticos. Conseqüentemente podem-se dividir as linhagens oriundas da mesma população em grupos heteróticos distintos e melhorar substancialmente a exploração da heterose. Han et al. (1991) e Terron et al. (1997) reportaram que é possível retirar linhagens e formar híbridos intrapopulacionais das populações de milho do CIMMYT, as quais possuem ampla base genética. Este trabalho teve como objetivo avaliar a capacidade de combinação de 18 linhagens $S_{3}$ de milho em cruzamentos dialélicos interpopulacional e alocá-las em grupos heteróticos distintos.

\section{MATERIAL E MÉTODOS}

Oito linhagens $S_{3}$ da população BR-105 e dez da população BR-106 foram utilizadas para esse estudo. Essas linhagens foram obtidas a partir de 400 linhagens $\mathrm{S}_{3}$ de cada população que foram avaliadas em cruzamentos dialélicos com a população recíproca, isto é, linhagens da população BR-105 x população BR-106, e vice-versa. De cada população foram selecionadas 40 linhagens, as quais foram avaliadas e selecionadas pelas suas performances per se e uniformidade.
Essas populações foram desenvolvidas pelo Centro Nacional de Milho e Sorgo (Embrapa Milho e Sorgo) e ambas apresentam ciclo precoce e baixa altura da planta. A população BR-105 possui grãos alaranjados duros e baixa depressão por endogamia. Originalmente foi denominada de Suwan, tendo sido obtida na Tailândia e derivada de um programa de seleção recorrente com progênies $S_{1}$ com alta intensidade de seleção. A população BR-106 possui grãos amarelos dentados e foi obtida pelo intercruzamento das variedades tardias e de porte alto, Centralmex, Composto Dentado e Maya, formando um composto. Posteriormente esse composto foi cruzado com a população BR-108 (Tuxpeño 1), de ciclo precoce e porte baixo. Após duas gerações de recombinação, seguiram-se três ciclos de seleção para redução da altura da planta e espiga. A população BR106 apresenta maior variabilidade genética que a BR-105.

Os 80 híbridos simples interpopulacionais foram avaliados em experimentos utilizando-se 0 delineamento experimental látice $10 \times 10$, aos quais foram adicionados 20 híbridos comerciais, perfazendo um total de 100 tratamentos. Os experimentos foram conduzidos no ano agrícola 1992/93, em três locais da região de Piracicaba/ SP (Depto. de Genética da ESALQ/USP, Fazenda Areão e Fazenda Caterpillar), com duas repetições por local e em duas épocas. Na análise de variância, cada combinação local/época foi considerada como um ambiente diferente. As parcelas foram constituídas por linhas de $4 \mathrm{~m}$ de comprimento, utilizando-se 0 espaçamento de $0,90 \mathrm{~m}$ entre linhas e $0,20 \mathrm{~m}$ entre plantas, sendo a área efetiva de $3,60 \mathrm{~m}^{2}$. Na semeadura foram colocadas 40 sementes por parcela e 15 dias após a germinação foi efetuado o desbaste, procurando-se manter o estande ideal de 20 plantas por parcela, resultando em uma densidade de aproximadamente 55.000 plantas ha ${ }^{-1}$. As adubações de plantio e cobertura, além do controle de plantas daninhas, foram realizados de acordo com o recomendado para a cultura, de acordo com a análise de solo. Os caracteres avaliados foram produção de grãos (PG), altura da planta (AP) e altura da espiga (AE). Para $P G$ as espigas de cada parcela foram colhidas e encaminhadas ao galpão aonde permaneceram em local seco até a uniformização da umidade. A correção do estande foi feita com base no estande médio pelo método da covariância (Vencovsky \& Barriga,1992).

Foram realizadas análises de variâncias individuais para cada experimento e a seguir, análises conjuntas considerando-se efeitos fixos para tratamentos e aleatórios para ambientes. As análises conjuntas foram realizadas utilizando-se médias de parcelas.

O método 4, modelo I de Griffing (1956) foi utilizado para a obtenção das estimativas da capacidade geral (CGC) e específica (CEC) de combinação, de acordo com o seguinte modelo matemático:

$Y_{i j k}=\mu+I_{k}+g_{i}+g_{j}+s_{i j}+(I g)_{i k}+(I g)_{j k}+(I s)_{i j k}+\bar{\varepsilon}_{i j k}$ 
em que $Y_{i j k}$ é o valor médio da combinação híbrida entre a i-ésima linhagem do grupo 1 (BR-106) e a j-ésima linhagem do grupo 2 (BR-105) no k-ésimo ambiente; $\mu$ é a média dos híbridos considerando-se todos os ambientes; $I_{k}$ é o efeito do k-ésimo ambiente; $g_{i}$ e $g_{j}$ são os efeitos das capacidades gerais de combinação da iésima e j-ésima linhagens dos grupos 1 e 2, respectivamente; $\mathrm{s}_{\mathrm{ij}}$ é efeito da capacidade específica de combinação entre as linhagens i e j, dos grupos 1 e 2, respectivamente; $\bar{\varepsilon}_{\mathrm{ijk}}$ é o erro experimental médio e os parâmetros restantes correspondem as interações entre ambientes e os efeitos das capacidades de combinação.

Os grupos heteróticos foram formados baseando-se nas estimativas das capacidades específicas de combinação (CEC) e na inspeção visual dos dendrogramas e dos gráficos resultantes das análises de agrupamento e de coordenadas principais. As estimativas de CEC foram consideradas como medidas de distância entre as linhagens, sendo que cruzamentos com efeitos de CEC positivos indicam que as linhagens pertencem a grupos heteróticos opostos e cruzamentos com efeitos de CEC negativos indicam que pertencem ao mesmo grupo heterótico. A partir da matriz das estimativas das capacidades específicas de combinação foi construído o dendrograma pelo método UPGMA (média aritmética não ponderada, Manly, 1994) e a dispersão gráfica dos dados foi realizada pelo método de ordenação de coordenadas principais (PCO, Manly, 1994), utilizando-se de um sistema de três coordenadas principais. Para a realização dessas análises utilizaramse também as estimativas de CEC das análises intrapopulacionais, pois a matriz das estimativas de CEC precisa estar completa devido as exigências dos programas computacionais. Essas análises foram obtidas utilizando-se o programa de análise estatística NTSYS (Numerical Taxonomy and Multivariate Analysis System), versão 2.0E (Rohlf, 1997).

Devido à presença de estimativas negativas das capacidades específicas de combinação, na realização das análises de agrupamento uma constante foi a elas adicionada. Essa constante apenas transformou os valores negativos em positivos, mas sem alterar a posição dessas estimativas. O ponto de corte determinado no dendrograma foi 9,9 , pois os valores das estimativas de CEC são muito próximos.

\section{RESULTADOS E DISCUSSÃO}

As médias dos experimentos para os caracteres peso de grãos (PG), altura da planta $(A P)$ e altura da espiga (AE) foram de 7,37 t ha ${ }^{-1}, 205,94 \mathrm{~cm} /$ planta e $105,56 \mathrm{~cm} /$ planta, respectivamente (TABELA 1). Os coeficientes de variação obtidos foram de $11,8 \%, 4,0 \%$, $6,3 \%$, para $P G, A P$ e $A E$, respectivamente, sendo considerados dentro dos limites aceitáveis na experimentação agrícola. Os valores dos coeficientes de variação das análises individuais (dados não mostrados) foram semelhantes aos da análise conjunta, indicando uma boa precisão na condução dos experimentos. As fontes de variação foram altamente significativas $(P<0,01)$ para todos os caracteres avaliados. Para $P G$, a significância da fonte de variação híbridos evidencia a existência de variação genética entre as linhagens, indicando que determinadas combinações são superiores às demais, pois os híbridos se comportaram de forma diferenciada. A interação tratamentos $x$ ambientes foi altamente significativa sugerindo que os híbridos não tiveram a mesma produção relativa em todos os ambientes.

As análises da capacidade de combinação detectaram efeitos altamente significativos para as capacidades gerais de combinação (CGC) e para as capacidades específicas de combinação (CEC), para todos os caracteres avaliados (TABELA 2). A contribuição da soma de quadrados da CGC, em relação à soma de quadrados total, foi de $81,7 \%, 94,9 \%$ e $92,6 \%$, respectivamente para $P G, A P$ e $A E$, na população $B R-$ 105 e $87,1 \%, 86,9 \%$ e $86,2 \%$ na população BR-106. Tais

TABELA 1 - Valores e significâncias dos quadrados médios das análises conjuntas de variâncias, para os híbridos interpopulacionais, para os caracteres produção de grãos (PG), altura da planta (AP) e altura da espiga (AE).

\begin{tabular}{|c|c|c|c|c|}
\hline \multirow[b]{2}{*}{ F. V. } & \multirow[b]{2}{*}{ G.L. } & \multicolumn{3}{|c|}{ Q.M } \\
\hline & & $P G$ & AP & $A E$ \\
\hline & & t ha $^{-1}$ & \multicolumn{2}{|c|}{ 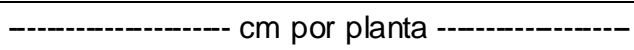 } \\
\hline Ambientes (A) & 5 & $40,44^{\star \star}$ & $32033,02^{\star \star}$ & $28306,67^{\star \star}$ \\
\hline Tratamentos $(\mathrm{T})$ & 99 & $0,52^{\star \star}$ & $530,50^{\star \star}$ & $270,35^{\star \star}$ \\
\hline Híbridos $(\mathrm{H})$ & 79 & $0,46^{* *}$ & $602,42^{\star *}$ & $295,62^{* *}$ \\
\hline Testemunhas $(T)$ & 19 & $0,54^{\star \star}$ & $202,32^{\star \star}$ & $125,77^{\star \star}$ \\
\hline T vs H & 1 & $5,12^{* \star}$ & $1084,07^{* *}$ & $1021,06^{* *}$ \\
\hline T vs $A$ & 495 & $0,10^{\star \star}$ & $69,00^{* \star}$ & $44,07^{\star \star}$ \\
\hline Erro efetivo médio & 486 & 0,06 & 53,44 & 30,37 \\
\hline Média & & 7,37 & 205,94 & 105,56 \\
\hline $\mathrm{CV} \%$ & & 11,82 & 4,03 & 6,29 \\
\hline
\end{tabular}

${ }^{\star *} \mathrm{P} \leq 0,01$ 
valores indicam a maior importância dos efeitos aditivos no controle desses caracteres. Resultados mostrando maior contribuição dos efeitos aditivos foram relatados por diversos autores para vários caracteres em milho (Naspolini Filho et al., 1981; Vasal et al., 1992a,b; Gama et al., 1995; Mariani \& Desidério, 1975). A significância dos quadrados médios para ambas as capacidades combinatórias indicam a existência de variabilidade entre os efeitos da CGC, associados a efeitos gênicos aditivos, e entre os efeitos da CEC, associados a efeitos gênicos não aditivos. A interação CGC x ambientes foi significativa para todos os caracteres, enquanto que a interação CEC $x$ ambientes foi significativa somente para PG.

As estimativas dos efeitos da CGC e o desviopadrão do contraste entre duas linhagens encontram-se na TABELA 3. Verifica-se para PG que $72,2 \%$ das linhagens apresentaram estimativas de CGC diferentes de zero, sendo que das oriundas da população BR-105, $75,0 \%$ apresentaram significância e das oriundas da população BR-106, 70,0\% apresentaram significância. Nota-se que se destacaram as linhagens 05 (BR-105) e 15 (BR-106) com magnitudes de CGC superiores às demais. Por outro lado, as linhagens 03, 04 e 08 da população BR-105 e as linhagens 09, 10 e 16 da população BR-106 apresentaram estimativas negativas de CGC e diferentes de zero, indicando que estas contribuíram para reduzir a produção nos cruzamentos. A amplitude de variação das estimativas de CGC foi de 7,86 e de 11,00 vezes o desvio-padrão nas populações BR-105 e BR-106, respectivamente.

Para o caráter AP, $77,8 \%$ das linhagens apresentaram estimativas de CGC diferentes de zero, sendo que das oriundas da população BR-105, 75,0\%

TABELA 2 - Valores e significâncias dos quadrados médios das análises conjuntas de variâncias para capacidade geral de combinação (CGC) e capacidade específica de combinação (CEC) para os caracteres produção de grãos (PG), altura da planta (AP) e altura da espiga (AE), relativas às linhagens das populações BR-105 e BR-106 avaliadas em cruzamentos interpopulacionais.

\begin{tabular}{|c|c|c|c|c|}
\hline \multirow[b]{2}{*}{ F.V. } & \multirow[b]{2}{*}{ G.L. } & \multicolumn{3}{|c|}{ Q.M. } \\
\hline & & $P G$ & AP & $\mathrm{AE}$ \\
\hline & & tha $^{-1}$ & ----- cm por & planta ----- \\
\hline Ambientes (A) & 5 & 32,54 & 25113,52 & 22233,40 \\
\hline C.G.C.1 (BR-106) & 9 & $1,55^{\star *}$ & $1246,59^{* *}$ & $704,85^{\star *}$ \\
\hline C.G.C.2 (BR-105) & 7 & $1,03^{\star *}$ & $3506,81^{* *}$ & $1419,34^{\star *}$ \\
\hline C.E.C. & 63 & $0,23^{\star *}$ & $187,69^{\star *}$ & $112,30^{\star *}$ \\
\hline C.G.C. $1 \times A$ & 45 & $0,17^{\star *}$ & $122,60^{* *}$ & $85,62^{* *}$ \\
\hline C.G.C. 2 × A & 35 & $0,13^{\star *}$ & $154,23^{\star *}$ & $78,01^{* *}$ \\
\hline C.E.C. $x A$ & 315 & $0,09^{* *}$ & $51,79^{\text {ns }}$ & $33,55^{\text {ns }}$ \\
\hline Erro médio & 486 & 0,06 & 53,44 & 30,37 \\
\hline
\end{tabular}

apresentaram significância e das oriundas da população BR-106, 80,0\% apresentaram significância. Destacaram-se as linhagens 03 (BR-105) e 17 (BR-106) com os maiores valores negativos de CGC. As linhagens 04 e $08 \mathrm{da}$ população BR-105 e as linhagens 10, 14, 17 e 18 da BR106 também apresentaram estimativas negativas de CGC diferentes de zero. A amplitude de variação das CGC's foi de 14,25 vezes o desvio-padrão na população BR-105 e de 9,54 vezes o desvio-padrão na população BR-106.

Para $A E, 88,9 \%$ das linhagens apresentaram estimativas de CGC diferentes de zero, sendo que das oriundas da população BR-105, 87,5\% apresentaram significância e das oriundas da população BR-106, 90,0\% apresentaram significância, destacando-se as linhagens 08 (BR-105) e 14 (BR-106) com os maiores valores negativos de CGC. As linhagens 03 e 04 da população BR-105 e as linhagens 10, 14, 15, 17 e 18 da BR-106 também apresentaram estimativas negativas de CGC diferentes de zero. A amplitude de variação das CGC's foi de 14,74 vezes o desvio-padrão na população BR-105 e 8,46 vezes o desvio-padrão na população BR-106.

TABELA 3 - Estimativas dos efeitos da capacidade geral de combinação $\hat{g}_{\mathrm{i}}$ e desvio padrão (D.P.) do contraste de duas linhagens, para os caracteres produção de grãos (PG), altura da planta (AP) e altura da espiga $(A E)$, relativas às linhagens das populações BR-105 e BR-106 avaliadas em cruzamentos dialélicos interpopulacionais.

\begin{tabular}{|c|c|c|c|c|}
\hline \multicolumn{2}{|l|}{ Linhagem } & \multirow{2}{*}{$\frac{P G}{t_{h a}^{-1}}$} & \multirow{2}{*}{$\begin{array}{c}\text { AP } \\
---\mathrm{cm} \text { por }\end{array}$} & \multirow{2}{*}{$\frac{\mathrm{AE}}{\text { anta ----.- }}$} \\
\hline & & & & \\
\hline \multirow[t]{8}{*}{ BR-105 } & 01 & $-0,007$ & 1,128 & 0,570 \\
\hline & 02 & $-0,039$ & $-0,879$ & $1,623^{\star}$ \\
\hline & 03 & $-0,207^{\star \star}$ & $-10,451^{\star *}$ & $-4,874^{\star \star}$ \\
\hline & 04 & $-0,096^{\star *}$ & $-4,912^{\star \star}$ & $-3,135^{\star \star}$ \\
\hline & 05 & $0,155^{\star \star}$ & $7,514^{\star \star}$ & $7,335^{\star \star}$ \\
\hline & 06 & $0,137^{\star *}$ & $8,559^{* \star}$ & $2,241^{\star \star}$ \\
\hline & 07 & $0,135^{\star *}$ & $7,993^{\star \star}$ & $3,739^{\star \star}$ \\
\hline & 08 & $-0,079 * *$ & $-8,952^{\star \star}$ & $-7,500^{\star \star}$ \\
\hline \multirow[t]{10}{*}{ BR-106 } & 09 & $-0,075^{\star}$ & $7,919^{* \star}$ & $5,537^{\star \star}$ \\
\hline & 10 & $-0,173^{\star \star}$ & $-3,151^{\star \star}$ & $-3,350^{\star \star}$ \\
\hline & 11 & $0,165^{\star *}$ & 0,164 & $1,375^{\star}$ \\
\hline & 12 & $0,105^{\star \star}$ & $-1,034$ & 0,117 \\
\hline & 13 & $0,161^{* *}$ & $4,655^{\star *}$ & $3,871^{\star *}$ \\
\hline & 14 & 0,031 & $-5,023^{\star \star}$ & $-3,983^{\star \star}$ \\
\hline & 15 & $0,170^{\text {** }}$ & $2,459^{\star}$ & $-2,817^{* *}$ \\
\hline & 16 & $-0,402^{\star *}$ & $5,956^{\star \star}$ & $5,422^{\star \star}$ \\
\hline & 17 & 0,010 & $-6,310^{* *}$ & $-3,841^{* *}$ \\
\hline & 18 & 0,008 & $-5,636^{\star \star}$ & $-2,331^{\star \star}$ \\
\hline D.P.1 $\left(\hat{\mathrm{g}}_{\mathrm{j}}-\hat{\mathrm{g}}_{\mathrm{j}^{\prime}}\right)$ & & 0,046 & 1,334 & 1,006 \\
\hline D.P.2 $\left(\hat{g}_{i}^{\prime}-\hat{g}_{i^{\prime}}\right)$ & & 0,052 & 1,492 & 1,125 \\
\hline
\end{tabular}

*, ** - significativo, respectivamente, a $5 \%$ e $1 \%$ pelo teste $t$; D.P.1 e D.P.2 - desvios-padrão do contraste entre as linhagens da BR-105 e BR-106, respectivamente. 
Observando-se todos os contrastes entre as estimativas de CGC para os três caracteres avaliados, verifica-se a presença de contrastes diferentes de zero, confirmando com isso, diferenças entre as estimativas.

As estimativas dos efeitos da capacidade específica de combinação (CEC) e as médias dos híbridos, para o caráter produção de grãos (PG), encontram-se na TABELA 4. Nota-se que 5,0\% dos cruzamentos apresentaram estimativas de CEC significativamente diferentes de zero, destacando-se os híbridos 04×09 e 05×16 com valores de CEC superiores aos demais. Os híbridos 05×09 e 04×16 apresentaram os valores negativos mais acentuados de CEC, sendo que esses também apresentaram baixa produção de grãos. A média de produção dos híbridos interpopulacionais foi de $6,80 \mathrm{t} \mathrm{ha}^{-1}$, variando de $3,81 \mathrm{t}$ $\mathrm{ha}^{-1}$ a $8,30 \mathrm{t} \mathrm{ha}^{-1}$. Verifica-se, também, um maior número de estimativas de CEC com valores positivos. Han et al. (1991) e Vasal et al. (1992c) reportaram que, em média, os cruzamentos das linhagens em nível interpopulacional têm mais efeitos positivos de CEC do que aqueles realizados em nível intrapopulacional, os quais tendem a apresentar mais efeitos negativos de CEC. Observando-se os contrastes entre as estimativas de $C E C$, verifica-se que alguns contrastes foram diferentes de zero.

Para o caráter AP, $5,0 \%$ das estimativas de CEC foram diferentes de zero (TABELA 5), destacandose híbridos $04 \times 16$ e $08 \times 09$ com valores negativos e diferentes de zero. A altura média das plantas foi de $206,61 \mathrm{~cm} /$ planta, variando de $188,43 \mathrm{~cm} /$ planta a
$229,79 \mathrm{~cm} /$ planta. Para o caráter AE, observa-se que $3,75 \%$ das estimativas de CEC foram diferentes de zero (TABELA 6), destacando-se os híbridos $04 \times 16$ e $08 \times 09$ que apresentaram efeitos de CEC inferiores aos demais. A média da altura da espiga foi de 106,21 $\mathrm{cm} /$ planta oscilando entre $93,58 \mathrm{~cm} /$ planta e 120,65 $\mathrm{cm} /$ planta.

Os grupos heteróticos foram formados baseando-se nas estimativas das capacidades específicas de combinação (CEC) as quais foram submetidas às análises de agrupamento e de coordenadas principais. A separação de linhagens em grupos heteróticos baseando-se em estimativas de capacidade específica de combinação tem sido amplamente utilizada no melhoramento de milho, embora sem utilizar análises de agrupamento e de coordenadas principais (Vasal et al., 1992c; Gonzalez et al., 1997; Terron et al., 1997).

Observando-se o dendrograma obtido da análise de agrupamento para o caráter peso de grãos (Figura 1), verifica-se que foram formados quatro grupos heteróticos (GI, Gll, GIII e GIV), sendo o Gl composto pelas linhagens 01, 03, 04, 05 e 08; o Gll pelas linhagens 09, 10, 13 e 15; o GIII pelas linhagens 02,06 e 07; e o GIV pelas linhagens 11, 12, 14, 17 e 18. Esse mesmo resultado também é confirmado através das análises de coordenadas principais (Figura 2). Devido ao grande número de linhagens, no gráfico em três dimensões a visualização dos grupos não é muito clara. Porém, no gráfico com dois eixos torna-se mais fácil a visualização dos grupos, onde vê-se claramente a separação das

TABELA 4 - Médias dos híbridos interpopulacionais entre linhagens das populações BR-105 e BR-106 para o caráter produção de grãos (PG em t ha-1) e estimativas da capacidade específica de combinação (CEC).

\begin{tabular}{|c|c|c|c|c|c|c|c|c|c|c|c|c|c|c|c|c|}
\hline L2 & & 01 & & 02 & & 03 & & 04 & & 05 & & 6 & & 07 & & 08 \\
\hline L1 & $P G$ & CEC & $P G$ & CEC & $P G$ & CEC & $P G$ & CEC & $P G$ & CEC & $P G$ & CEC & $P G$ & CEC & $P G$ & CEC \\
\hline 09 & 7,100 & 0,201 & 6,732 & 0,084 & 6,148 & 0,018 & 7,390 & $0,403^{\star}$ & 5,680 & $-0,528^{* *}$ & 6,978 & 0,008 & 7,420 & 0,185 & 6,672 & $-0,372$ \\
\hline 10 & 6,031 & $-0,128$ & 6,189 & $-0,034$ & 5,960 & 0,044 & 6,031 & $-0,041$ & 6,774 & 0,003 & 6,900 & 0,074 & 6,799 & 0,037 & 6,287 & 0,045 \\
\hline 11 & 7,134 & $-0,026$ & 6,600 & $-0,207$ & 6,865 & 0,063 & 6,950 & $-0,012$ & 7,600 & $-0,003$ & 8,000 & 0,178 & 7,443 & $-0,047$ & 7,164 & 0,055 \\
\hline 12 & 6,793 & $-0,105$ & 6,570 & $-0,158$ & 6,600 & 0,022 & 6,600 & 0,092 & 7,589 & 0,054 & 7,680 & 0,107 & 7,821 & 0,166 & 6,885 & 0,005 \\
\hline 13 & 7,524 & 0,131 & 6,800 & $-0,124$ & 6,600 & $-0,034$ & 6,970 & 0,001 & 7,411 & $-0,072$ & 7,473 & $-0,033$ & 7,720 & 0,069 & 7,162 & 0,061 \\
\hline 14 & 6,690 & 016 & 7,163 & 0,149 & 6,840 & 0,190 & 823 & $-0,118$ & 7,530 & 0,105 & 6,352 & $-0,215$ & 6,920 & $-0,121$ & 6,750 & 0,026 \\
\hline 15 & 6,941 & $-0,110$ & 7,500 & 0,146 & 5,149 & $-0,112$ & 7,890 & 0,360 & 8,300 & 0,273 & 7,073 & $-0,202$ & 7,174 & $-0,160$ & 6,552 & $-0,194$ \\
\hline 16 & 6,332 & 0,217 & 5,900 & 0,077 & 4,648 & $-0,251$ & 3,810 & $-0,698^{* *}$ & 7,187 & $0,402^{*}$ & 6,530 & 0,154 & 5,789 & $-0,137$ & 6,179 & 0,236 \\
\hline 17 & 6,720 & $-0,038$ & 6,613 & $-0,049$ & 6,420 & 0,042 & 6,934 & 0,136 & 7,070 & $-0,060$ & 6,851 & $-0,128$ & 7,352 & 0,075 & 6,694 & 0,021 \\
\hline 18 & 6,493 & $-0,126$ & 7,200 & 0,116 & 6,352 & 0,017 & 6,743 & 0,061 & 6,784 & $-0,174$ & 7,310 & 0,056 & 7,000 & $-0,067$ & 6,921 & 0,117 \\
\hline
\end{tabular}

$\begin{array}{llll}\text { D.P. } 1: 0,139 & \text { D.P. } 2: 0,137 & \text { D.P. } 3: 0,129\end{array}$

${ }^{*},{ }^{* *}$ - significativo, respectivamente, a $5 \%$ e $1 \%$ de probabilidade, pelo teste t; L1 e L2 - linhagens das populações BR-106 e BR-105, respectivamente; D.P. $1=\sqrt{V\left(\hat{S}_{i j}-S_{i k}\right)}$ em que $\mathrm{j}$ e $\mathrm{k}$ referem-se à $L 1$ e i à $L 2$, D.P.2 $=\sqrt{V\left(\hat{S}_{i j}-\hat{S}_{k j}\right)}$ em que $\mathrm{i}$ e $\mathrm{k}$ referem-se à $L 2$ e $\mathrm{j}$ à $L 1$ e D.P.3 $=\sqrt{V\left(\hat{S}_{i j}-\hat{S}_{k l}\right)}$ em que i e $k$ referem-se à L2 e j e I à L2 - desvios-padrão do contraste entre as linhagens da BR-105 e BR-106, respectivamente. 
linhagens da população BR-106 em dois grupos. Para as linhagens da população BR-105 a separação ficou mais clara quando se consideraram as duas primeiras coordenadas principais $(25,2 \%)$. As três primeiras coordenadas principais refletiram apenas $34,8 \%$ da variação total. Portanto, na separação das linhagens em grupos heteróticos também deve-se levar em consideração a análise de agrupamento a qual é visualizada por meio do dendrograma. Ressalte-se, que a linhagem 16 foi desconsiderada nesses grupos devido à falhas na tabela dialélica nas análises intrapopulacionais.

As médias de produção de cada grupo e dos cruzamentos entre os grupos encontram-se na TABELA 7. As médias dos cruzamentos intergrupos superaram as médias dos grupos, com exceção do grupo II. A média dos cruzamentos envolvendo todas as linhagens também foi inferior às médias dos cruzamentos intergrupos, mostrando que a realização de determinados cruzamentos dirigidos resultariam em melhores híbridos. As estimativas médias de CEC foram negativas para todos os grupos e também para os cruzamentos GlxGll e GIIIxGIV, sendo que para esses cruzamentos a CEC foi de baixa magnitude.

Separadamente, tanto a análise de coordenadas principais como a análise de agrupamento (dendrograma) podem gerar dúvidas na alocação de linhagens aos seus grupos heteróticos. $\mathrm{Na}$ análise de coordenadas principais geralmente são utilizadas as três primeiras coordenadas as quais podem não conter a maior parte da variação, e no dendrograma pode-se ter dificuldades de leitura. Assim, utilizando-se em conjunto as duas metodologias as dúvidas podem ser diminuídas e a alocação das linhagens aos seus respectivos grupos heteróticos pode ser feita com menor margem de erro. Portanto, para se obter um resultado mais preciso, seria recomendável a utilização dos dois métodos.

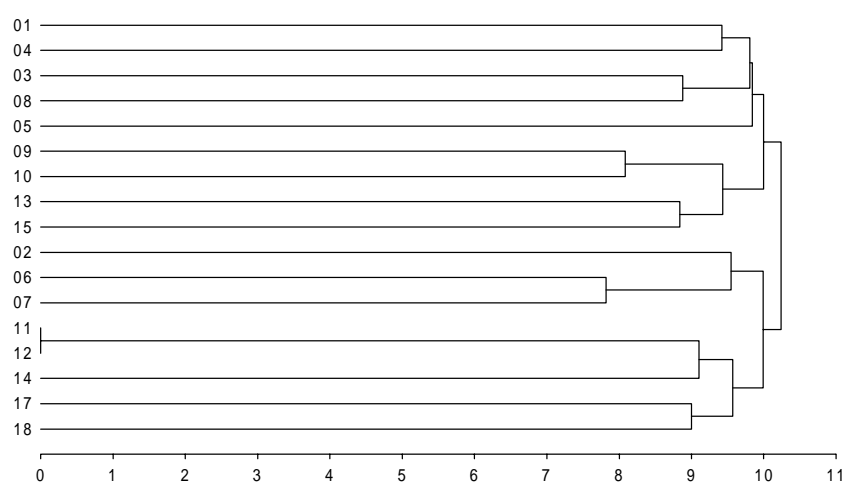

Figura 1 - Dendrograma das linhagens de milho das populações BR105 e BR-106 agrupadas segundo o método UPGMA, para o caráter produção de grãos.

TABELA 5 - Médias dos híbridos interpopulacionais entre linhagens das populações BR-105 e BR-106 para o caráter altura da planta (AP em cm/planta) e estimativas da capacidade específica de combinação (CEC).

\begin{tabular}{|c|c|c|c|c|c|c|c|c|c|c|c|c|c|c|c|c|}
\hline L2 & 0 & 1 & 0 & & 0 & 3 & & 04 & 0 & 5 & 0 & 6 & 07 & & & 08 \\
\hline L1 & $P G$ & CEC & $P G$ & CEC & $P G$ & CEC & $P G$ & CEC & $P G$ & CEC & $P G$ & CEC & $P G$ & CEC & $P G$ & CEC \\
\hline 09 & 220,713 & 5,053 & 218,703 & 5,050 & 203,213 & $-0,867$ & 214,013 & 4,393 & 219,177 & $-2,869$ & 221,035 & $-2,056$ & 198,723 & 7,264 & 229,788 & $-15,969^{* *}$ \\
\hline 10 & 209,115 & 4,525 & 199,212 & $-3,371$ & 197,605 & 4,594 & 198,079 & $-0,471$ & 209,969 & $-1,007$ & 211,082 & $-0,939$ & 212,270 & 0,815 & 190,365 & $-4,145$ \\
\hline 11 & 203,203 & $-4,702$ & 207,773 & 1,875 & 195,893 & $-0,433$ & 204,484 & 2,619 & 215,375 & 1,084 & 219,843 & 4,507 & 206,763 & $-8,006$ & 200,880 & 3,054 \\
\hline 12 & 206,193 & $-0,514$ & 202,463 & $-2,236$ & 197,288 & 2,160 & 200,973 & 0,306 & 216,118 & 3,025 & 210,200 & $-3,938$ & 216,059 & 2,488 & 195,336 & $-1,291$ \\
\hline 13 & 223,767 & 1,005 & 221,674 & 0,899 & 202,268 & $-9,252$ & 213,401 & $-4,088$ & 191,564 & 2,891 & 202,589 & 3,940 & 189,611 & 4,332 & 223,592 & 0,272 \\
\hline 14 & 210,566 & $-1,579$ & 206,746 & $-1,987$ & 201,139 & 3,030 & 204,112 & $13,888^{*}$ & 194,170 & $-2,359$ & 192,949 & $-6,036$ & 214,970 & $-5,267$ & 204,315 & 0,310 \\
\hline 15 & 203,337 & $-6,862$ & 214,179 & 5,986 & 198,929 & 0,308 & 207,334 & 3,174 & 219,896 & 3,309 & 208,439 & $-9,192$ & 215,484 & $-1,580$ & 204,977 & 4,857 \\
\hline 16 & 220,265 & 6,683 & 222,640 & 3,280 & 192,039 & 3,290 & 220,380 & $-15,618^{* *}$ & 205,409 & 2,557 & 207,239 & $-0,862$ & 192,659 & $-2,952$ & 217,609 & 3,622 \\
\hline 17 & 211,976 & $-1,792$ & 204,568 & $-2,059$ & 197,568 & $-1,735$ & 199,639 & 2,176 & 188,118 & $-3,249$ & 192,244 & 3,114 & 211,288 & 2,652 & 210,948 & 0,893 \\
\hline 18 & 220,998 & $-1,818$ & 205,109 & $-7,438$ & 189,684 & $-1,095$ & 200,286 & $-6,380$ & 189,430 & $-3,382$ & 200,422 & $11,462^{*}$ & 197,365 & 0,255 & 209,224 & 8,397 \\
\hline
\end{tabular}

D.P. $1: 4,004$

D.P. $2: 3,948$

D.P. $3: 3,715$

${ }^{*},{ }^{* \star}$ - significativo, respectivamente, a 5\% e 1\%, pelo teste $t$; L1 e L2 - linhagens das populações BR-106 e BR-105, respectivamente; D.P. $1=\sqrt{V\left(\hat{S}_{i j}-\hat{S}_{i k}\right)}$ em que j e $\mathrm{k}$ referem-se à $L 1$ e i à $L 2, D . P .2=\sqrt{V\left(\hat{S}_{i j}-\hat{S}_{k j}\right)}$ em que i e k referem-se à $L 2$ e j à $L 1$ e D.P.3 $=\sqrt{V\left(\hat{S}_{i j}-\hat{S}_{k l}\right)}$ em que i e k referem-se à L2 e j e I à L2 - desvios-padrão do contraste entre as linhagens da BR-105 e BR-106, respectivamente. 
TABELA 6 - Médias dos híbridos interpopulacionais entre linhagens das populações BR-105 e BR-106 para o caráter altura da espiga ( $A E$ em $\mathrm{cm} /$ planta) e estimativas da capacidade específica de combinação (CEC).

\begin{tabular}{|c|c|c|c|c|c|c|c|c|c|c|c|c|c|c|c|c|}
\hline \multirow{2}{*}{$\frac{\mathrm{L} 2}{\mathrm{~L} 1}$} & \multicolumn{2}{|c|}{01} & \multicolumn{2}{|c|}{02} & \multicolumn{2}{|c|}{03} & \multicolumn{2}{|c|}{04} & \multicolumn{2}{|c|}{05} & \multicolumn{2}{|c|}{06} & \multicolumn{2}{|c|}{07} & \multicolumn{2}{|c|}{08} \\
\hline & $P G$ & CEC & $P G$ & CEC & $P G$ & CEC & $P G$ & CEC & $P G$ & CEC & $P G$ & CEC & $P G$ & CEC & $P G$ & CEC \\
\hline 09 & 117,301 & 4,976 & 114,518 & 1,140 & 104,768 & $-2,113$ & 115,189 & 6,569 & 115,354 & $-3,736$ & 112,668 & $-1,327$ & 100,896 & 5,161 & 120,655 & $-10,671^{*}$ \\
\hline 10 & 105,975 & 2,537 & 103,273 & $-1,217$ & 104,558 & 6,564 & 97,727 & $-2,006$ & 105,545 & $-4,658$ & 102,563 & $-2,545$ & 105,791 & $-0,815$ & 97,508 & 2,140 \\
\hline 11 & 104,552 & $-3,610$ & 110,862 & 1,646 & 104,516 & 1,798 & 103,122 & $-1,335$ & 118,436 & 3,509 & 112,388 & 2,555 & 105,556 & $-5,774$ & 101,302 & 1,210 \\
\hline 12 & 106,064 & $-0,840$ & 107,918 & $-0,039$ & 103,189 & 1,728 & 101,513 & $-1,686$ & 119,952 & 6,282 & 106,336 & $-2,239$ & 109,768 & $-0,304$ & 95,932 & $-2,902$ \\
\hline 13 & 116,155 & $-1,698$ & 119,622 & 0,564 & 104,872 & $-6,840$ & 108,960 & $-2,082$ & 98,375 & 2,198 & 104,689 & 3,826 & 93,584 & 1,932 & 115,759 & 2,100 \\
\hline 14 & 109,141 & $-0,330$ & 106,746 & $-2,961$ & 102,474 & 1,100 & 99,560 & $10,041^{*}$ & 98,461 & $-2,714$ & 95,645 & $-4,915$ & 118,124 & $-1,132$ & 104,840 & 0,911 \\
\hline 15 & 100,069 & $-3,901$ & 110,266 & 5,242 & 99,215 & 0,689 & 105,499 & 5,233 & 112,937 & 2,201 & 99,728 & $-5,913$ & 103,338 & $-3,800$ & 96,149 & 0,249 \\
\hline 16 & 114,447 & 4,142 & 118,444 & 4,862 & 97,662 & 0,753 & 116,351 & $-10,842^{*}$ & 107,519 & $-0,530$ & 106,700 & 0,567 & 97,702 & $-1,513$ & 113,864 & 2,561 \\
\hline 17 & 106,620 & 0,937 & 107,650 & $-1,430$ & 98,182 & $-2,431$ & 103,883 & $-1,059$ & 95,071 & $-2,061$ & 94,278 & 2,003 & 112,276 & 4,639 & 110,753 & $-0,598$ \\
\hline 18 & 114,114 & $-2,214$ & 110,730 & $-7,807$ & 97,918 & $-1,248$ & 102,242 & $-2,834$ & 97,764 & $-0,491$ & 101,386 & 7,987 & 102,569 & 1,608 & 109,233 & 5,000 \\
\hline
\end{tabular}

D.P. $1: 3,018$

D.P.2: 2,976

D.P.3: 2,801

${ }^{*},{ }^{* *}$ - significativo, respectivamente, a 5\% e 1\%, pelo teste t; L1 e L2 - linhagens das populações BR-106 e BR-105, respectivamente D.P. $1=\sqrt{V\left(\hat{S}_{i j}-\hat{S}_{i k}\right)}$ em que j e $\mathrm{k}$ referem-se à $L 1$ e i à $L 2, D . P .2=\sqrt{V\left(\hat{S}_{i j}-\hat{S}_{k j}\right)}$ em que i e k referem-se à $L 2$ e j à $L 1$ e D.P.3 $=\sqrt{V\left(\hat{S}_{i j}-\hat{S}_{k l}\right)}$ em que i e k referem-se à L2 e j e I à L2 - desvios-padrão do contraste entre as linhagens da BR-105 e BR-106, respectivamente.

TABELA 7 - Médias de produção de grãos (PG) e médias das estimativas da capacidade específica de combinação (CEC) para todas as linhagens, para os diferentes grupos e para os híbridos interpopulacionais intergrupos.

\begin{tabular}{|c|c|c|c|}
\hline $\begin{array}{l}\text { Combinação da } \\
\text { Linhagem }\end{array}$ & $\mathrm{N}$ & $P G$ & CEC \\
\hline & & t ha $^{-1}$ & \\
\hline Entre todas as linhagens & 136 & 6,48 & 0,000 \\
\hline $\begin{array}{l}\text { Grupo I (Gl) - BR-105 } \\
(01,03,04,05,08)\end{array}$ & 10 & 6,46 & $-0,309$ \\
\hline $\begin{array}{l}\text { Grupo II (GII) - BR-106 } \\
(09,10,13,15)\end{array}$ & 06 & 7,08 & $-0,891$ \\
\hline $\begin{array}{l}\text { Grupo III (GIII) - BR-105 } \\
(02,06,07)\end{array}$ & 03 & 5,32 & $-1,029$ \\
\hline $\begin{array}{l}\text { Grupo IV (GN) - BR-106 } \\
(11,12,14,17,18)\end{array}$ & 10 & 3,64 & $-0,535$ \\
\hline GI x Gll - inter & 20 & 6,73 & $-0,002$ \\
\hline GI x GIII - intra & 15 & 6,97 & 0,412 \\
\hline Gl x GN - inter & 25 & 6,87 & 0,013 \\
\hline GIl x GIll - inter & 12 & 7,06 & 0,004 \\
\hline Gll x GIV - intra & 20 & 6,76 & 0,535 \\
\hline GIII $\times$ GN - inter & 15 & 7,12 & $-0,009$ \\
\hline
\end{tabular}

$\mathrm{N}$ = número de combinações.

A linhagem 16 foi excluída por causa de perdas de dados.
As linhagens das populações BR-105 e BR-106 foram alocadas em quatro grupos heteróticos distintos, sendo dois grupos formados somente por linhagens da população BR-105 e os outros dois formados por linhagens da população BR-106. A separação de grupos heteróticos dentro de cada população mostra um refinamento na seleção das linhagens para a formação de híbridos de milho, o que pode ser confirmado observando-se as médias e as estimativas de CEC dos cruzamentos entre os grupos formados (TABELA 7). Verifica-se que os cruzamentos entre os grupos apresentaram boa produtividade e as estimativas de CEC foram positivas na maioria dos cruzamentos, com exceção de GIxGll e GIllxGIV, que apesar de negativos, os valores eram próximos de zero, mostrando que dentro das populações existe variabilidade suficiente para a formação de grupos heteróticos. Portanto, com base nos resultados obtidos com este material e nas condições deste trabalho, concluiu-se que a separação das linhagens em grupos heteróticos a partir das estimativas de CEC, utilizando-se as análises de agrupamento e de coordenadas principais, foi eficiente.

Para os caracteres altura da planta e altura da espiga os agrupamentos com base nas estimativas de CEC não foram coincidentes com os agrupamentos obtidos para o caráter produção de grãos, sendo que ocorreu uma mistura das linhagens e essas não 


\section{REFERÊNCIAS BIBLIOGRÁFICAS}
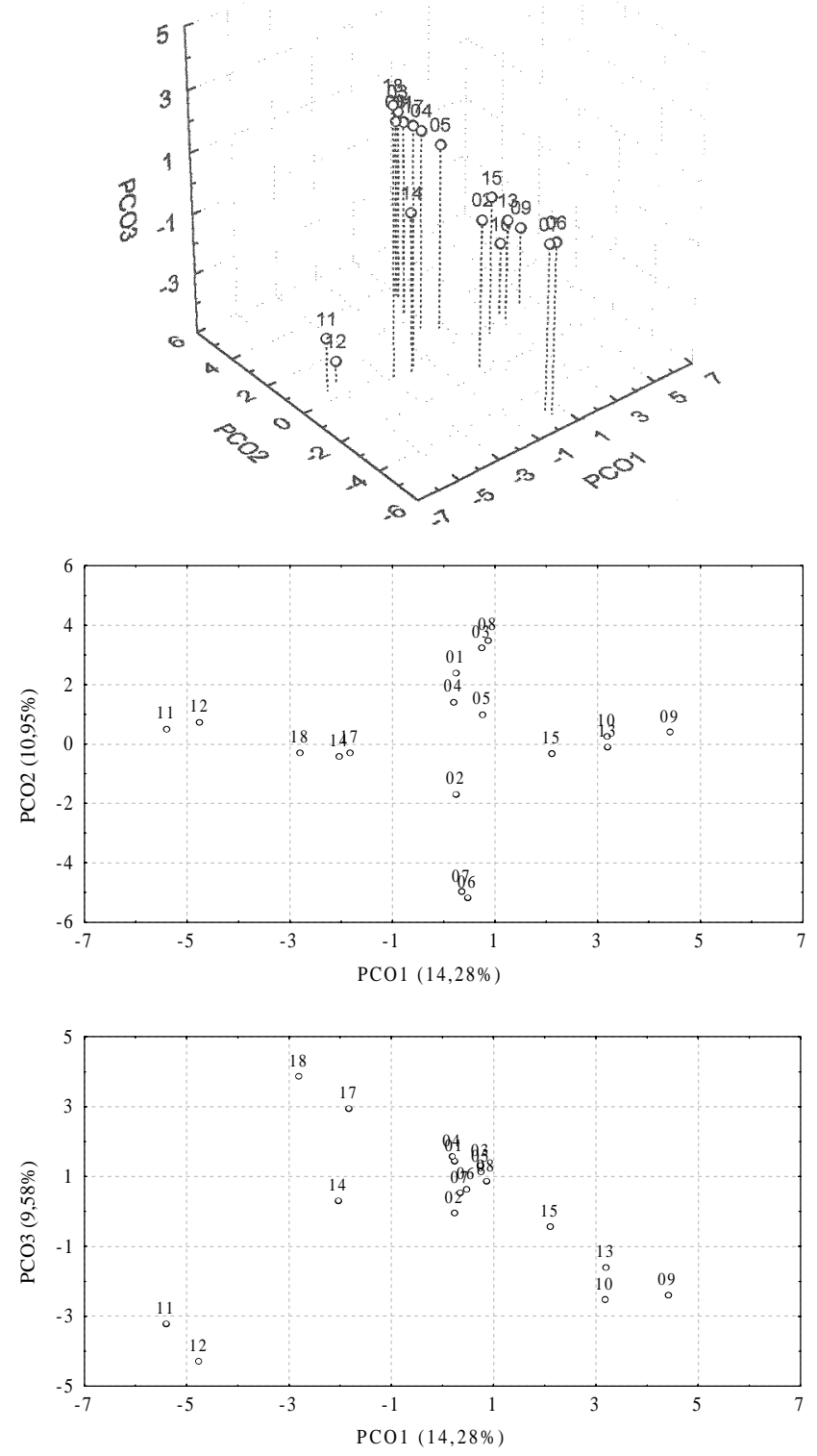

Figura 2 - Associação das linhagens de milho das populações BR105 e BR-106 reveladas por análise de coordenadas principais (PCO) a partir das estimativas das capacidades específicas de combinação para o caráter produção de grãos.

apresentaram um padrão heterótico definido (dados não mostrados). O caráter produção de grãos possui um elevado valor de grau médio de dominância e, como a capacidade específica de combinação depende dos efeitos de dominância, a alocação das linhagens em grupos heteróticos a partir de estimativas de CEC foi eficiente. Devido aos caracteres AP e AE apresentarem um baixo valor de grau médio de dominância, não foi possível discriminar as linhagens em grupos heteróticos a partir de estimativas de CEC.
GAMA, E.E.G.; HALLAUER, A.R.; FERRÃO, R.G.; BARBOSA, D.M. Heterosis in maize single crosses derived from a yellow Tuxpeño variety in Brazil. Revista Brasileira de Genética, v.18, p.81-85, 1995.

GONZALEZ, S.; CÓRDOVA, H.; RODRIGUEZ, S.; DE LEON, H.; SERRATO, V.M. Determinacion de un patron heterotico a partir de la evaluacion de un dialelo de diez lineas de maiz subtropical. Agronomia Mesoamericana, v.8, p.1-7, 1997.

GRIFFING, B. Concept of general and specific combining ability in relation to diallel crossing systems. Australian Journal of Biological Science, v.9, p.463-493, 1956.

HALLAUER, A.R. Methods using in developing maize inbreds. Maydica, v.35, p.1-16, 1990.

HAN, G.C.; VASAL, S.K.; BECK, D.L.; ELIAS, E. Combining ability of inbred lines derived from CIMMYT maize (Zea mays L.) germplasm. Maydica, v.36, p.57-64, 1991.

MANLY, B.F.J. Multivariate statistical methods. 2.ed. New Delhi: Thomson Press, 1994. 215p.

MARIANI, G.; DESIDÉRIO, E. Grain yield and prolificacy in maize. 2. A diallel analysis of eight inbreds from the O.P. variety Nostrono Dell' Isola at two densities. Maydica, v.20, p.95-110, 1975.

NASPOLINI FILHO, V.; GAMA, E.E.G.; VIANNA, R.T.; MÔRO, J.R. General and specific combining ability for yield in a diallel cross among 18 maize populations (Zea mays L.). Revista Brasileira de Genética, v.4, p.571-577, 1981.

ROHLF, F. J. NTSYS-pc numerical taxonomy and multivariate analysis system: version 2.0. New York: Exeter Publications, 1997.

SMITH, O.S. Covariance between line per se and testcross performance. Crop Science, v.26, p.540-543, 1986.

SOUZA JR., C.L.; SANTOS, M.X.; MAGNAVACA, R.; GAMA, E. E.G. Estimativas de parâmetros genéticos na interpopulação de milho BR-105 x BR-106 e suas implicações no melhoramento. Pesquisa Agropecuária Brasileira, v.28, p.473-479, 1993.

SPRAGUE, G.F.; TATUM, L.A. General vs specific combining ability in single crosses on corn. Journal of the American Society of Agronomy, v.34, p.923-932, 1942.

TERRON, A.; PRECIADO, E.; CÓRDOVA, H.; MICKELSON, H.; LÓPEZ, R. Determinacion del patron heterotico de 30 lineas de maiz derivadas de la poblacion 43SR del CIMMYT. Agronomia Mesoamericana, v.8, p.26-34, 1997.

VASAL, S.K.; SRINVASAN, G.; CROSSA, J.; BECK, D.L. Heterosis and combining ability of CIMMYT's subtropical and temperate early-maturity maize germplasm. Crop Science, v.32, p.884-890, 1992a.

VASAL, S.K.; SRINVASAN, G.; GONZÁLEZ, C.F.; HAN, G.C.; PANDEY, S.; BECK, D.L.; CROSSA, J. Heterosis and combining ability of CIMMYT's tropical $x$ subtropical maize germplasm. Crop Science, v.32, p.1483-1489, 1992b.

VASAL, S.K.; SRINVASAN, G.; HAN, G.C.; GONZALEZ, C.F. Heterotic patterns of eighty-eight white subtropical CIMMYT maize lines. Maydica, v.37, p.319-327, 1992c.

VENCOVSKY, R.; BARRIGA, P. Genética biométrica no fitomelhoramento. Ribeirão Preto: Sociedade Brasileira de Genética, 1992. 486p.

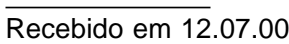

